\title{
Combined efficacy of C-reactive protein and red blood cell distribution width in prognosis of patients with culture-negative infective endocarditis
}

\author{
Xue-biao Wei ${ }^{1, *}$, Yuan-hui Liu ${ }^{1,}{ }^{*}$, Peng-cheng He ${ }^{1}$, Ying-ling Zhou ${ }^{1}$, Ning Tan ${ }^{1}$, Ji-yan \\ Chen ${ }^{1}$ and Dan-qing $\mathbf{Y u}^{1}$ \\ ${ }^{1}$ Department of Cardiology, Guangdong Cardiovascular Institute, Guangdong Provincial Key Laboratory of Coronary \\ Heart Disease Prevention, Guangdong General Hospital, Guangdong Academy of Medical Sciences, Guangzhou 510100, \\ Guangdong, China \\ *These authors contributed equally to this work and co-first authors \\ Correspondence to: Dan-qing Yu, email: gdydq100@126.com \\ Ning Tan, email: gdtanning@126.com
}

Keywords: infective endocarditis, c-reactive protein, red blood cell distribution width, outcome

Received: July 14, 2016 Accepted: March 27, $2017 \quad$ Published: April 06, 2017

Copyright: Wei et al. This is an open-access article distributed under the terms of the Creative Commons Attribution License 3.0 (CC BY

3.0 ), which permits unrestricted use, distribution, and reproduction in any medium, provided the original author and source are credited.

\section{ABSTRACT}

Objective: To evaluate the combined effect of C-reactive protein (CRP) and red blood cell distribution width (RDW) on the prediction of in-hospital and long-term poor outcomes in patients with blood culture-negative infective endocarditis (BCNE).

Results: Patients with high CRP and high RDW has the highest incidence of in-hospital death $(2.3 \%$ vs. $7.8 \%$ vs. $5.6 \%$ vs. $17.5 \%, P<0.001)$. CRP $>17.8 \mathrm{mg} / \mathrm{L}$ (odds ratio $[\mathrm{OR}]=2.41,95 \%$ confidence interval $[\mathrm{CI}], 1.06-5.51, P=0.037$ ), RDW >16.3 (OR $=2.29,95 \% C I, 1.10-4.77, P=0.027)$, and these two values in combination ( $O R=3.15,95 \% C I, 1.46-6.78, P=0.003$ ) were independently associated with in-hospital death. Patients with RDW $>16.3$ had higher long-term mortality $(P=0.003)$, while no significant correlation was observed for CRP $(P=0.151)$.

Materials and Methods: In total, 572 participants with BCNE were consecutively enrolled. They were classified into four groups based on the optimal CRP and RDW cutoff values (which were determined using a receiver operating characteristic analysis): low CRP and low RDW $(n=216)$, high CRP and low RDW $(n=129)$, low CRP and high RDW ( $n=107)$, and high CRP and high RDW $(n=120)$.

Conclusions: Increased CRP and RDW, especially in combination, are independently associated with in-hospital death in BCNE. RDW, but not CRP, has long-term prognostic value.

\section{INTRODUCTION}

Despite intensive antibiotic therapy and aggressive surgical intervention, infective endocarditis (IE) remains a serious and potentially life-threatening condition [1]. The mortality rate of IE is about $20 \%$ after initial admission and up to $40 \%$ after 5 years [2-4]. Early detection of high-risk patients is essential for improving prognosis. Furthermore, among IE patients, 5-69.7\% are blood culture-negative with relatively poor outcomes, particularly in developing countries [5-7]. However, limited studies to date have focused on this patient population.
Several factors, including old age, contribute to high mortality and morbidity rates in IE patients [8-10]. In addition, elevation of C-reactive protein (CRP) and red blood cell distribution width (RDW) have been shown to be associated, at least partly, with poor outcomes in IE patients [11-14]. Nevertheless, the results in the literature to date are inconclusive, and numerous factors, such as different investigation protocols and study sample sizes, have been suggested to explain these discrepancies. The present study was aimed at evaluating the predictive value of combined CRP and RDW for outcomes of patients with blood culture-negative infective endocarditis (BCNE). 


\section{RESULTS}

\section{Baseline clinical characteristics based on CRP and RDW}

In-hospital death was recorded for 42 of the 572 patients $(72.0 \%$ men aged $45 \pm 15$ years, range, $18-83$ years) definitely diagnosed as having BCNE. In the ROC analysis, CRP $>17.8 \mathrm{mg} / \mathrm{L}$ showed a sensitivity of $76.2 \%$ and a specificity of $58.3 \%$ for predicting in-hospital death (AUC $=0.696,95 \%$ CI, 0.620-0.772, $P<0.001$ ). RDW $>16.3 \%$ showed a sensitivity of $64.3 \%$ and a specificity of $62.3 \%$ (AUC $=0.641,95 \%$ CI, $0.564-0.718$, $P=0.002)$. We observed no significant differences between CRP and RDW in predicting in-hospital death (AUC: 0.696 vs. 0.641, $P=0.308$; Figure 1). AUC for combined CRP and RDW was $0.712(95 \% \mathrm{CI}, 0.638-0.785, P<0.001)$ with a sensitivity of $78.6 \%$ and specificity of $59.8 \%$, and did not achieve better performance than RDW only (AUC: 0.712 vs. $0.641, P=0.056$ ).

Patients were divided into four groups according to the optimal cut-off values of CRP and RDW, specifically, 216 with low CRP and low RDW, 129 with high CRP and low RDW, 107 with low CRP and high RDW and 120 with high CRP and high RDW. Patients with low CRP and high RDW were more likely to be female and those with low CRP and low RDW to have a history of IE. In addition, lower rates of prior antibiotic use and New York Heart Association (NYHA) class III-IV were seen in patients with low CRP and low RDW. Higher levels of serum creatinine were detected in patients with high CRP and high RDW displaying lower concentrations of hemoglobin. Patients with high CRP were associated with higher erythrocyte sedimentation rate (ESR) and white blood count (WBC). Overall, 451 (78.8\%) patients received surgical treatment, with the lowest rate recorded for the subgroup of patients with high CRP and high RDW ( $88.4 \%$ vs. $72.9 \%$ vs. $78.5 \%$ vs. $68.3 \%, P<0.001)$. Moreover, in-hospital death rates $(2.3 \%$ vs. $7.8 \%$ vs. $5.6 \%$ vs. $17.5 \%, P<0.001)$ and MACEs $(10.2 \%$ vs. $24.8 \%$ vs. $17.8 \%$ vs. $38.3 \%, P<0.001)$ were significantly higher in patients with high CRP and high RDW, relative to the other subgroups. All surviving patients were followed up for a median of 32.4 (13.7-54.0) months (65 lost to follow-up). We observed statistical differences among the groups in terms of long-term mortality ( $4.9 \%$ vs. $6.7 \%$ vs. $10.2 \%$ vs. $14.9 \%, P=0.032$ ) (Table 1 ).

Patients with high RDW were more likely to have a long disease course (symptoms $>1$ month). Subgroup analysis for patients with symptoms for $>1$ month or not was additionally performed. CRP was higher in the inhospital death patient group, regardless of the duration of IE. However, differences in RDW were only observed in patients with symptoms $\leq 1$ month.

\section{Predictive value of CRP and RDW for adverse outcomes}

Univariate logistic regression identified age (odds ratio $[\mathrm{OR}]=1.05, P<0.001), \mathrm{WBC}(\mathrm{OR}=1.06, P=0.028)$,

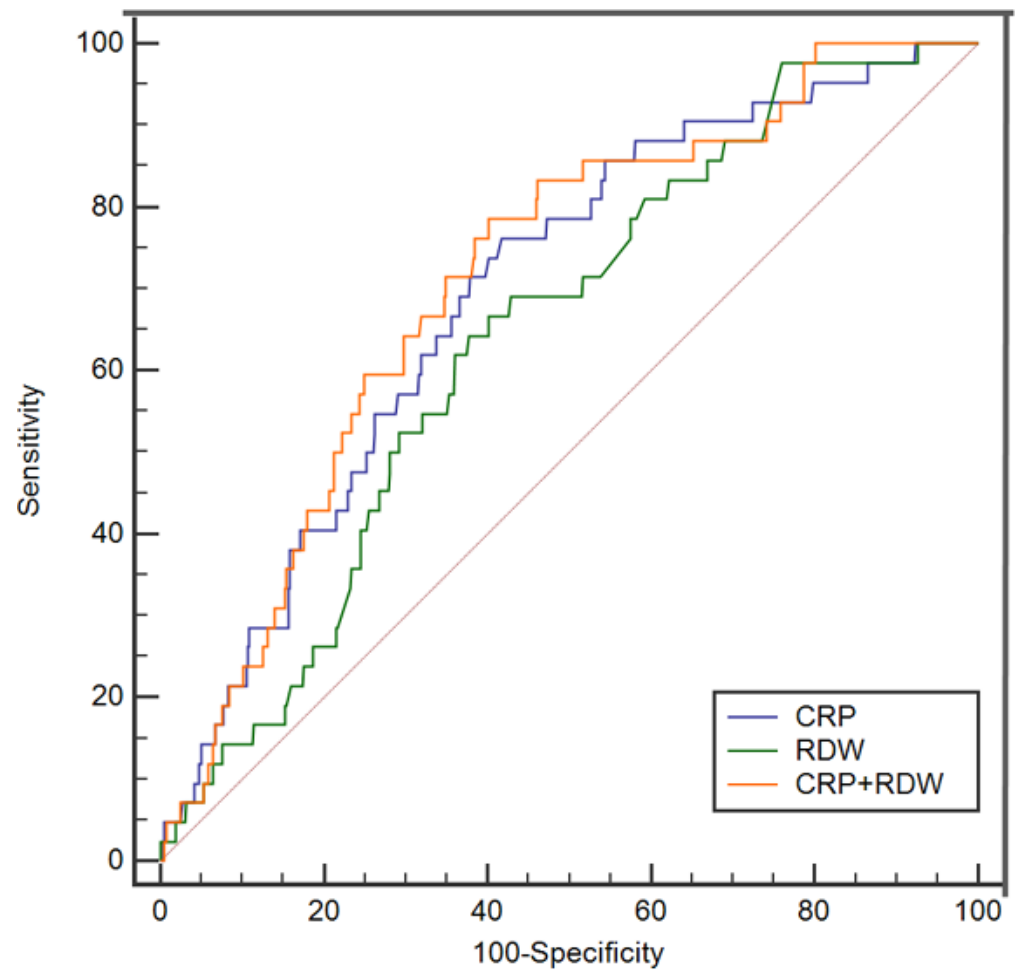

Figure 1: The ROC curves for CRP and RDW in predicting in-hospital death. 
Table 1: Baseline clinical characteristics of patients according to CRP and RDW

\begin{tabular}{|c|c|c|c|c|c|}
\hline Clinical variables & $\begin{array}{l}\text { Low CRP, Low } \\
\text { RDW }(n=216)\end{array}$ & $\begin{array}{l}\text { High CRP, Low } \\
\text { RDW }(n=129)\end{array}$ & $\begin{array}{l}\text { Low CRP, High } \\
\text { RDW }(n=107)\end{array}$ & $\begin{array}{l}\text { High CRP, High } \\
\text { RDW }(n=120)\end{array}$ & $P$-value \\
\hline Age (year) & $44.4 \pm 13.9$ & $47.1 \pm 15.6$ & $44.3 \pm 14.5$ & $43.4 \pm 16.1$ & 0.227 \\
\hline Males, $n(\%)$ & $161(74.5)$ & $102(79.1)$ & $64(59.8)$ & $85(70.8)$ & 0.008 \\
\hline Hypertension, $n(\%)$ & $34(15.7)$ & $20(15.5)$ & $9(8.4)$ & $15(12.5)$ & 0.283 \\
\hline Diabetes mellitus, $n(\%)$ & $9(4.2)$ & $10(7.8)$ & $8(7.5)$ & $10(8.3)$ & 0.375 \\
\hline Previous IE & $24(11.1)$ & $2(1.6)$ & $4(3.7)$ & $9(7.5)$ & 0.004 \\
\hline Prior antibiotic use & $102(47.2)$ & $83(64.3)$ & $68(63.6)$ & $74(61.7)$ & 0.003 \\
\hline Prosthetic valves & $9(4.2)$ & $9(7.0)$ & $8(7.5)$ & $6(5.0)$ & 0.552 \\
\hline Symptoms $>1$ month & $131(60.6)$ & $52(40.3)$ & $70(65.4)$ & $59(49.2)$ & $<0.001$ \\
\hline NYHA III-IV, $n(\%)$ & $61(28.2)$ & $49(38.0)$ & $41(38.3)$ & $64(53.3)$ & $<0.001$ \\
\hline \multicolumn{6}{|l|}{ Affected valve } \\
\hline Aortic & $75(34.7)$ & $51(39.5)$ & $36(33.6)$ & $37(30.8)$ & 0.538 \\
\hline Mitral & $89(41.2)$ & $49(38.0)$ & $40(37.4)$ & $51(42.5)$ & 0.809 \\
\hline Aortic+Mitral & $13(6.0)$ & $10(7.8)$ & $11(10.3)$ & $17(14.2)$ & 0.080 \\
\hline Others & $22(10.2)$ & $7(5.4)$ & $14(13.1)$ & $13(10.8)$ & 0.233 \\
\hline Paravalvular abscess & $7(3.2)$ & $12(9.3)$ & $6(5.6)$ & $8(6.7)$ & 0.128 \\
\hline $\mathrm{CRP}, \mathrm{mg} / \mathrm{L}$ & $3.6(1.9,7.5)$ & $41.3(27.7,69.8)$ & $7.7(4.3,12.9)$ & $39.9(26.5,71.3)$ & $<0.001$ \\
\hline $\mathrm{ESR}, \mathrm{mm} / \mathrm{h}$ & $10.0(4.0,28.0)$ & $54.0(26.0,81.0)$ & $25.0(7.0,51.3)$ & $57.0(28.0,95.0)$ & $<0.001$ \\
\hline Creatinine, umol/L & $84.2 \pm 26.7$ & $83.4 \pm 23.1$ & $90.2 \pm 48.9$ & $98.7 \pm 51.1$ & 0.003 \\
\hline $\mathrm{WBC}\left(* 10^{\wedge} 9 / \mathrm{L}\right)$ & $7.4 \pm 2.7$ & $10.9 \pm 4.8$ & $8.4 \pm 3.3$ & $11.7 \pm 6.0$ & $<0.001$ \\
\hline Hemoglobin, g/L & $128.6 \pm 20.6$ & $109.4 \pm 18.6$ & $105.5 \pm 21.3$ & $95.3 \pm 17.8$ & $<0.001$ \\
\hline RDW (\%) & $14.2 \pm 1.1$ & $14.5 \pm 1.0$ & $19.1 \pm 2.7$ & $19.5 \pm 3.2$ & $<0.001$ \\
\hline LVEF (\%) & $65.0 \pm 8.4$ & $64.6 \pm 8.5$ & $63.8 \pm 8.2$ & $63.7 \pm 9.7$ & 0.539 \\
\hline Vegetation size $>10 \mathrm{~mm}$ & $79(36.6)$ & $62(48.1)$ & $48(44.9)$ & $66(55.0)$ & 0.009 \\
\hline Surgical treatment & $191(88.4)$ & $94(72.9)$ & $84(78.5)$ & $82(68.3)$ & $<0.001$ \\
\hline \multicolumn{6}{|l|}{ Type of surgery } \\
\hline Bioprosthesis & $30(15.7)$ & $11(11.7)$ & $18(21.4)$ & $12(14.6)$ & \\
\hline Mechanical prosthesis & $131(68.6)$ & $70(74.5)$ & $58(69.0)$ & $62(75.6)$ & \\
\hline Repair & $30(15.7)$ & $13(13.8)$ & $9(9.5)$ & $8(9.8)$ & 0.432 \\
\hline \multicolumn{6}{|l|}{ In-hospital events } \\
\hline Embolic events & $11(5.1)$ & $15(11.6)$ & $7(6.5)$ & $16(13.3)$ & 0.030 \\
\hline Stroke & $7(3.2)$ & $10(7.8)$ & $5(4.7)$ & $9(7.5)$ & 0.212 \\
\hline Death & $5(2.3)$ & $10(7.8)$ & $6(5.6)$ & $21(17.5)$ & $<0.001$ \\
\hline MACEs & $22(10.2)$ & $32(24.8)$ & $19(17.8)$ & $46(38.3)$ & $<0.001$ \\
\hline Long-term mortality & $9(4.9)$ & $7(6.7)$ & $9(10.2)$ & $13(14.9)$ & 0.032 \\
\hline
\end{tabular}

Abbreviations: IE, infective endocarditis; NYHA, New York Heart Association; CRP, C-reactive protein; ESR, erythrocyte sedimentation rate; WBC, white blood count; RDW, red cell distribution width; LVEF, left ventricular ejection fraction; MACEs, major adverse clinical events.

$\mathrm{eGFR}<90 \mathrm{~mL} / \mathrm{min} / 1.73 \mathrm{~m}^{2}(\mathrm{OR}=3.26, P=0.001), \mathrm{LVEF}$ $(\mathrm{OR}=0.95, P=0.001)$, surgical treatment $(\mathrm{OR}=0.12$, $P<0.001)$, CRP $(\mathrm{OR}=1.01, P=0.001)$ and $\mathrm{RDW}$ $(\mathrm{OR}=1.12, P=0.007)$ as significant predictors for inhospital death. In multivariate analysis, CRP $>17.8 \mathrm{mg} / \mathrm{L}$ $(\mathrm{OR}=2.41,95 \% \mathrm{CI}, 1.06-5.51, P=0.037)$ and $\mathrm{RDW}>16.3(\mathrm{OR}=2.29,95 \% \mathrm{CI}, 1.10-4.77, P=0.027)$ were found to independently predict in-hospital mortality, with the combination of CRP and RDW being the strongest predictor $(\mathrm{OR}=3.15,95 \% \mathrm{CI}, 1.46-6.78$, $P=0.003)$. Other factors, including age, LVEF and surgical treatment, were significantly associated with in-hospital mortality (Table 2).

Kaplan-Meier analysis showed a higher cumulative rate of long-term death in patients with $\mathrm{RDW}>16.3$ (log rank $=8.67, P=0.003)$. However, this association was not observed for CRP $(\log$ rank $=2.06, P=0.151$; Figure 2). 


\section{DISCUSSION}

To our knowledge, the present study is the first to assess the combined effect of CRP and RDW in predicting adverse outcomes in patients with BCNE. CRP $>17.8 \mathrm{mg} / \mathrm{L}$ and RDW $>16.3$ had significant predictive value for in-hospital death, especially when both factors were combined. In addition, RDW had long-term prognostic value in this patient group, but not CRP.

The prognosis of IE has improved considerably in the past few decades owing to intensive antimicrobial therapy and aggressive surgical intervention. Several risk factors have been identified and used for risk stratification [15-18]. However, in-hospital and long-term mortality remain high, particularly in patients with BCNE. BCNE accounts for 5-69.7\% IE cases [19], and is independently associated with postoperative late survival and events $[6,20]$.

Accordingly, identification of patients at moderate or high risk should further improve prognosis. IE is not only an inflammatory entity, but also a condition associated with an autoimmune disorder characterized by elevation of multiple inflammatory markers. Importantly, previous epidemiological studies have reported that increased CRP or RDW level, inflammatory markers, are strongly related to adverse clinical outcomes [11-13] in IE patients. Data from the current study were consistent with these earlier findings.

CRP corresponds to the severity of the underlying disease, while RDW is an index of red blood cell size heterogeneity and it is elevated under conditions of ineffective production and increased destruction of erythrocytes due to inflammatory factors or increased oxidative stress [21, 22]. Therefore, continued increase in $\mathrm{CRP}$ and RDW may reflect unfavorable and uncontrollable disease conditions, which expose patients to higher risk of poorer outcome. Increased CRP and RDW, particularly in combination, were independently associated with inhospital death in the present study. While the combined usage of CRP and RDW did not achieve better performance than RDW alone, its prognostic value was greater (AUC: 0.712 vs. 0.641 ), signifying that the combination of CRP and RDW could provide a more powerful tool for risk stratification. In clinical practice, patients presenting with $\mathrm{BCNE}$ are also at high risk of poor outcomes and may be administered intensive antimicrobial therapy or aggressive surgical intervention in cases with high CRP and RDW.

Our data showed that increased RDW, but not CRP, is associated with high long-term mortality. The underlying mechanisms are yet to be established. The main potential explanation is that CRP is an acute-phase reactant. The level of CRP increases during acute inflammation, which may be suppressed through antimicrobial therapy. However, Lappé et al. [23] demonstrated that RDW is associated with chronic inflammation with no significant increase in CRP. In addition, RDW levels may be affected by pathophysiological mechanisms except inflammation, such as oxidative stress $[24,25]$, facilitating the ability to predict underlying co-morbidities. Therefore, RDW, a simple and inexpensive test, may present a reliable marker for predicting in-hospital and long-term mortality in patients with BCNE.

The present study was a retrospective investigation based on prospective data and had a number of limitations, such as the small sample size from a single center
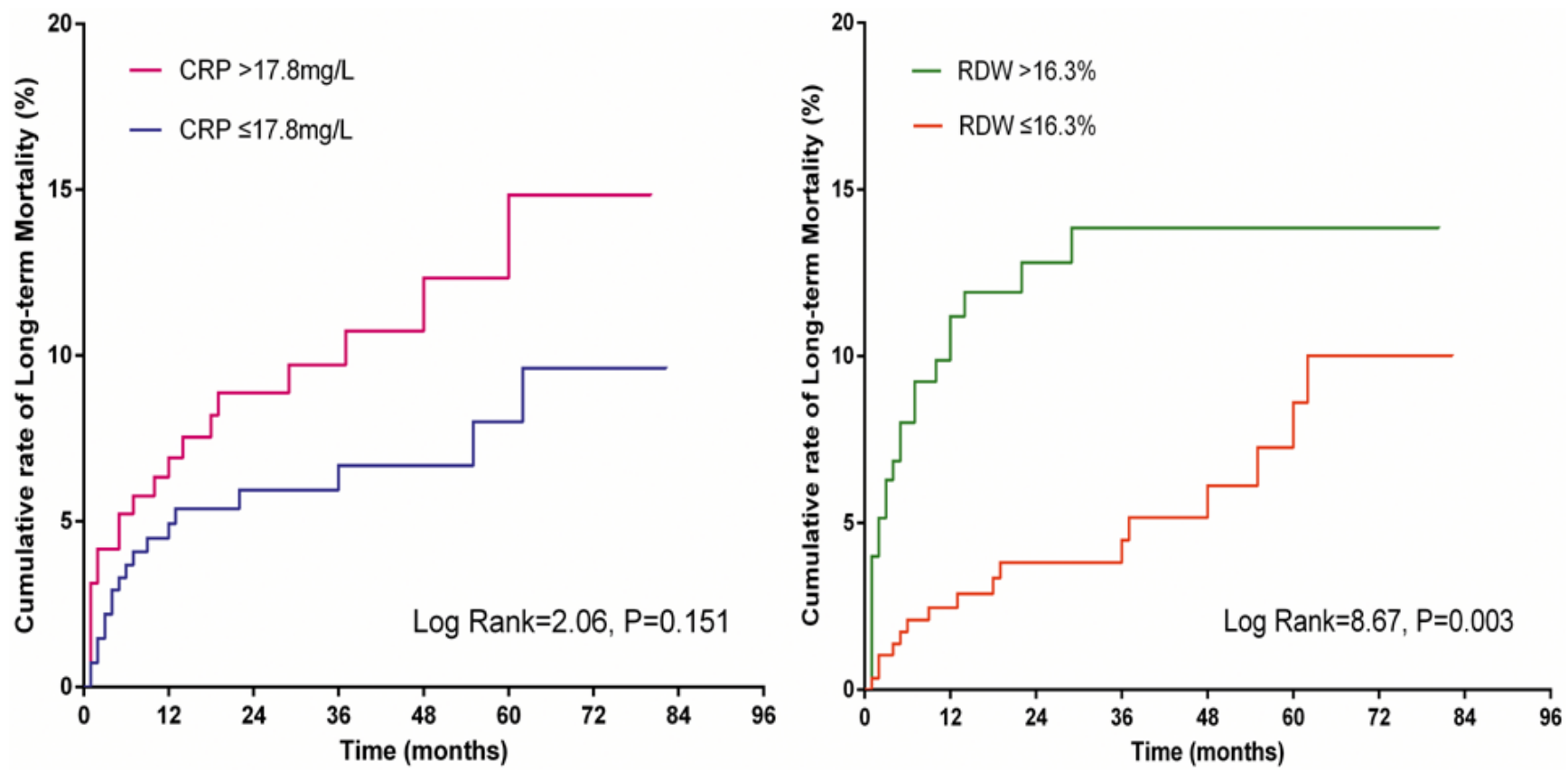

Figure 2: Kaplan-Meier curves of CRP and RDW for long-term mortality. 
Table 2: Risk factors of in-hospital death by multivariate logistic regression

\begin{tabular}{|c|c|c|c|}
\hline Clinical variables & Odds ratio & $\begin{array}{l}95 \% \text { Confidence } \\
\text { interval (CI) }\end{array}$ & $p$-value \\
\hline \multicolumn{4}{|l|}{ Model 1} \\
\hline Age (year) & 1.03 & $1.01,1.06$ & 0.021 \\
\hline $\mathrm{WBC}\left(* 10^{9} / \mathrm{L}\right)$ & 1.09 & $1.03,1.16$ & 0.005 \\
\hline eGFR $<90 \mathrm{ml} / \mathrm{min} / 1.73 \mathrm{~m} 2$ & 2.15 & $0.98,4.71$ & 0.055 \\
\hline $\operatorname{LVEF}(\%)$ & 0.96 & $0.92,0.99$ & 0.015 \\
\hline Surgical treatment & 0.17 & $0.08,0.34$ & $<0.001$ \\
\hline \multicolumn{4}{|l|}{ Model 2} \\
\hline $\mathrm{CRP}>17.8 \mathrm{mg} / \mathrm{L}$ & 2.41 & $1.06,5.51$ & 0.037 \\
\hline Age (year) & 1.03 & $1.00,1.05$ & 0.040 \\
\hline $\mathrm{WBC}\left(* 10^{9} / \mathrm{L}\right)$ & 1.07 & $1.00,1.14$ & 0.061 \\
\hline eGFR $<90 \mathrm{ml} / \mathrm{min} / 1.73 \mathrm{~m} 2$ & 2.14 & $0.97,4.70$ & 0.059 \\
\hline $\operatorname{LVEF}(\%)$ & 0.96 & $0.93,1.00$ & 0.032 \\
\hline Surgical treatment & 0.20 & $0.10,0.41$ & $<0.001$ \\
\hline \multicolumn{4}{|l|}{ Model 3} \\
\hline RDW $>16.3 \%$ & 2.29 & $1.10,4.77$ & 0.027 \\
\hline Age (year) & 1.03 & $1.01,1.06$ & 0.015 \\
\hline WBC $\left(* 10^{9} / \mathrm{L}\right)$ & 1.08 & $1.01,1.15$ & 0.018 \\
\hline eGFR $<90 \mathrm{ml} / \mathrm{min} / 1.73 \mathrm{~m} 2$ & 1.97 & $0.89,4.35$ & 0.094 \\
\hline LVEF (\%) & 0.96 & $0.92,0.99$ & 0.017 \\
\hline Surgical treatment & 0.18 & $0.09,0.36$ & $<0.001$ \\
\hline \multicolumn{4}{|l|}{ Model 4} \\
\hline $\mathrm{CRP}>17.8 \mathrm{mg} / \mathrm{L}$ and $\mathrm{RDW}>16.3 \%$ & 3.15 & $1.46,6.78$ & 0.003 \\
\hline Age (year) & 1.03 & $1.01,1.06$ & 0.015 \\
\hline $\mathrm{WBC}\left(* 10^{9} / \mathrm{L}\right)$ & 1.06 & $0.99,1.13$ & 0.090 \\
\hline eGFR $<90 \mathrm{ml} / \mathrm{min} / 1.73 \mathrm{~m} 2$ & 1.95 & $0.88,4.32$ & 0.098 \\
\hline LVEF (\%) & 0.96 & $0.93,1.00$ & 0.044 \\
\hline Surgical treatment & 0.19 & $0.09,0.39$ & $<0.001$ \\
\hline
\end{tabular}

Abbreviations: WBC, white blood count; eGFR, estimated glomerular filtration rate; LVEF, left ventricular ejection fraction; CRP, C-reactive protein; RDW, red cell distribution width; age, WBC and LVEF were continuous variables here.

and inclusion of BCNE patients only. Therefore, our conclusions may not be applicable to BCNE patients. Since CRP and RDW were not dynamically monitored, we were unable to ascertain whether marker changes were associated with adverse outcome. Future randomized trials are warranted to confirm whether decreasing CRP and RDW levels below the cut-off points determined in our study would lead to better outcomes.

\section{MATERIALS AND METHODS}

\section{Patient enrollment and data collection}

Patients confirmed with IE according to modified Duke criteria [26] were prospectively enrolled from
Guangdong General Hospital, Guangzhou, China, between January 2009 and July 2015. Patients with a history of serious liver dysfunction and hematological disease, except anemia, were excluded. A total of 1293 patients diagnosed with IE were screened, among which 108 were younger than 18 years and 120 were repeatedly hospitalized. Two patients diagnosed as IE after major cardiac surgery during hospitalization, one with missing RDW data, and 155 with no CRP measurements were excluded. We additionally excluded 329 patients with culture-positive IE. In addition, patients with estimated glomerular filtration rate $(\mathrm{eGFR})<15 \mathrm{~mL} / \mathrm{min} / 1.73 \mathrm{~m}^{2}$ $(n=6)$ were excluded to eliminate interference of serious renal dysfunction, finally resulting in 572 participants. The study was approved by the Research Ethics Committee of 
Guangdong General Hospital (2016434H). All participants provided written informed consent.

Fasting venous blood was collected after suspected IE, and RDW, CRP and other blood indices measured accordingly. CRP was calculated using an immunonephelometric method (IMMAGE 800, Beckman Coulter, USA; normal range, $0-8 \mathrm{mg} / \mathrm{L}$ ), and RDW was estimated using an automated blood cell counter (LH780, Beckman Coulter, USA; normal range, 11-16\%). Blood was collected from at least three venipuncture sites for cultures, and it was injected into two bottles with specific media for aerobic and anaerobic organisms, respectively. The results were automatically monitored using a blood culture machine. We additionally accepted the results of blood cultures from other centers in cases where patients were transferred to our hospital. Transthoracic M-mode, two-dimensional and Doppler evaluation were routinely performed within $24 \mathrm{~h}$ after admission. Left ventricular ejection fraction (LVEF) was determined with the biplane Simpson's method. Vegetation size was measured in different echocardiographic windows and the longest vegetation diameter obtained. eGFR was calculated using the 4-variable Modification of Diet in Renal Disease equation for Chinese patients [27].

Surgery was performed in cases where surgical criteria were met. However, under conditions of extremely poor health or unacceptably high risk and fee of operation, conservative drug therapy was initiated.

Demographic and clinical characteristics of enrolled participants were collected by one researcher with the aid of an electronic case report form and confirmed independently.

\section{Follow-up and endpoints}

After discharge, all surviving patients were followed up through telephone interviews at least half a year. The primary end point was in-hospital mortality. Secondary end points were long-term all-cause mortality and inhospital major adverse clinical events (MACEs), including renal dialysis, embolic events, acute heart failure or death. Long-term mortality was defined as all-cause death after discharge to the deadline of follow-up.

\section{Statistical analysis}

In total, 572 participants with BCNE were classified into four groups based on the optimal cutoff values of CRP and RDW determined from receiver operating characteristic analysis: low CRP and low RDW (CRP $<17.8 \mathrm{mg} / \mathrm{L}$ and $\mathrm{RDW}<16.3 \%, n=216)$, high CRP and low RDW (CRP $>17.8 \mathrm{mg} / \mathrm{L}$ and RDW $<16.3 \%$, $n=129)$, low CRP and high RDW (CRP $<17.8 \mathrm{mg} / \mathrm{L}$ and RDW $>16.3 \%, n=107)$, high CRP and high RDW $(\mathrm{CRP}>17.8 \mathrm{mg} / \mathrm{L}$ and $\mathrm{RDW}>16.3 \%, n=120)$. Continuous data were presented as means \pm SD and compared using analysis of variance (ANOVA) when normally distributed and otherwise with the Wilcoxon rank-sum test expressed as median and quartile range. Categorical data were presented as a percentage and compared using $\chi^{2}$ or Fisher's exact test. Indices with $P<0.05$ in univariate analysis were used for multivariate logistic regression analysis, and cutoff points with high sensitivity and specificity confirmed via receiver operator characteristic (ROC) curve analysis. Areas under the curve (AUC) were compared using $\mathrm{z}$ statistics [28]. Statistical analyses were performed using SPSS software version 13.0 (SPSS, Inc., Chicago, Illinois). Values of $P<0.05$ were considered significant.

\section{CONCLUSIONS}

In patients with BCNE, high CRP and RDW, especially in combination, are independently associated with in-hospital death. Early identification of patients with $\mathrm{BCNE}$ at higher risk of in-hospital complications using the combination of CRP and RDW may improve therapeutic choices and consequent outcomes. Furthermore, RDW has long-term prognostic value in patients with $\mathrm{BCNE}$, but not CRP.

\section{Abbreviations}

$\mathrm{CRP}, \mathrm{C}$-reactive protein; RDW, red cell distribution width; BCNE, blood culture-negative infective endocarditis; OR, odds ratio; CI, confidence interval; IE, infective endocarditis; eGFR, estimated glomerular filtration rate; LVEF, left ventricular ejection fraction; MACEs, major adverse clinical events; NYHA, New York Heart Association; ESR, erythrocyte sedimentation rate; WBC, white blood count.

\section{Authors' contributions}

Dan-qing Yu and Ning Tan contributed to the conception or design of the work. Peng-cheng $\mathrm{He}$ and Ying-ling Zhou contributed to the acquisition, analysis, or interpretation of data for the work. Xue-biao Wei and Yuan-hui Liu drafted the manuscript. Dan-qing Yu and Jiyan Chen critically revised the manuscript. All the authors gave final approval and agreed to be accountable for all aspects of work ensuring integrity and accuracy.

\section{ACKNOWLEDGMENTS}

None.

\section{CONFLICTS OF INTEREST}

The authors declare no conflicts of interest. 


\section{FUNDING}

No funding was in this study.

\section{REFERENCES}

1. Klein M, Wang A. Infective Endocarditis. J Intensive Care Med. 2016; 31: 151-163.

2. Lalani T, Chu VH, Park LP, Cecchi E, Corey GR, DuranteMangoni E, Fowler VJ, Gordon D, Grossi P, Hannan M, Hoen B, Munoz P, Rizk H, et al. In-hospital and 1-year mortality in patients undergoing early surgery for prosthetic valve endocarditis. JAMA Intern Med. 2013; 173:1495-1504.

3. Fernandez-Hidalgo N, Almirante B, Tornos P, GonzalezAlujas MT, Planes AM, Galinanes M, Pahissa A. Immediate and long-term outcome of left-sided infective endocarditis. A 12-year prospective study from a contemporary cohort in a referral hospital. Clin Microbiol Infect. 2012; 18:E522-E530.

4. Ternhag A, Cederstrom A, Torner A, Westling K. A nationwide cohort study of mortality risk and long-term prognosis in infective endocarditis in Sweden. PLOS ONE. 2013; 8:e67519.

5. Habib G, Lancellotti P, Antunes MJ, Bongiorni MG, Casalta JP, Del ZF, Dulgheru R, El KG, Erba PA, Iung B, Miro JM, Mulder BJ, Plonska-Gosciniak E, et al. 2015 ESC Guidelines for the management of infective endocarditis: The Task Force for the Management of Infective Endocarditis of the European Society of Cardiology (ESC). Endorsed by: European Association for Cardio-Thoracic Surgery (EACTS), the European Association of Nuclear Medicine (EANM). Eur Heart J. 2015; 36:3075-3128.

6. Lamas CC, Fournier PE, Zappa M, Brandao TJ, Januarioda-Silva CA, Correia MG, Barbosa GI, Golebiovski WF, Weksler C, Lepidi H, Raoult D. Diagnosis of blood culturenegative endocarditis and clinical comparison between blood culture-negative and blood culture-positive cases. Infection. 2016; 44:459-466.

7. Naber CK, Erbel R. Infective endocarditis with negative blood cultures. Int J Antimicrob Agents. 2007; 30:S32-S36.

8. San RJ, Lopez J, Vilacosta I, Luaces M, Sarria C, Revilla A, Ronderos R, Stoermann W, Gomez I, Fernandez-Aviles F. Prognostic stratification of patients with left-sided endocarditis determined at admission. Am J Med. 2007; 120:361-369.

9. Chirillo F, Bacchion F, Pedrocco A, Scotton P, De Leo A, Rocco F, Valfre C, Olivari Z. Infective endocarditis in patients with diabetes mellitus. J Heart Valve Dis. 2010; 19:312-320.

10. Spies C, Madison JR, Schatz IJ. Infective endocarditis in patients with end-stage renal disease: clinical presentation and outcome. Arch Intern Med. 2004; 164:71-75.
11. Turak O, Canpolat U, Ozcan F, Yayla C, Mendi MA, Oksuz F, Tok D, Tok D, Cagli K, Golbasi Z. D-dimer level predicts in-hospital mortality in patients with infective endocarditis: a prospective single-centre study. Thromb Res. 2014; 134:587-592.

12. Heiro M, Helenius H, Sundell J, Koskinen P, Engblom E, Nikoskelainen J, Kotilainen P. Utility of serum C-reactive protein in assessing the outcome of infective endocarditis. Eur Heart J. 2005; 26:1873-1881.

13. Guray Y, Ipek EG, Guray U, Demirkan B, Kafes H, Asarcikli LD, Cabuk G, Yilmaz MB. Red cell distribution width predicts mortality in infective endocarditis. Arch Cardiovasc Dis. 2014; 107:299-307.

14. Turak O, Ozcan F, Isleyen A, Basar FN, Gul M, Yilmaz S, Sokmen E, Yuzgecer H, Lafci G, Topaloglu S, Aydogdu S. Usefulness of neutrophil-to-lymphocyte ratio to predict inhospital outcomes in infective endocarditis. Can J Cardiol. 2013; 29:1672-1678.

15. Castillo JC, Anguita MP, Ramirez A, Siles JR, Torres F, Mesa D, Franco M, Munoz I, Concha M, Valles F. Long term outcome of infective endocarditis in patients who were not drug addicts: a 10 year study. Heart. 2000; 83:525-530.

16. Galvez-Acebal J, Almendro-Delia M, Ruiz J, de Alarcon A, Martinez-Marcos FJ, Reguera JM, Ivanova-Georgieva R, Noureddine M, Plata A, Lomas JM, de la Torre-Lima J, Hidalgo-Tenorio C, Luque $\mathrm{R}$, et al. Influence of early surgical treatment on the prognosis of left-sided infective endocarditis: a multicenter cohort study. Mayo Clin Proc. 2014; 89:1397-1405.

17. Curlier E, Hoen B, Alla F, Selton-Suty C, Schubel L, Doco-Lecompte T, Minary L, Erpelding ML, Duval X, Chirouze C. Relationships between sex, early valve surgery and mortality in patients with left-sided infective endocarditis analysed in a population-based cohort study. Heart. 2014; 100:1173-1178.

18. Rasmussen RV, Bruun LE, Lund J, Larsen CT, Hassager C, Bruun NE. The impact of cardiac surgery in native valve infective endocarditis: can euroSCORE guide patient selection? Int J Cardiol. 2011; 149:304-309.

19. Fournier PE, Thuny F, Richet H, Lepidi H, Casalta JP, Arzouni JP, Maurin M, Celard M, Mainardi JL, Caus T, Collart F, Habib G, Raoult D. Comprehensive diagnostic strategy for blood culture-negative endocarditis: a prospective study of 819 new cases. Clin Infect Dis. 2010; 51:131-140.

20. Murashita T, Sugiki H, Kamikubo Y, Yasuda K. Surgical results for active endocarditis with prosthetic valve replacement: impact of culture-negative endocarditis on early and late outcomes. Eur J Cardiothorac Surg. 2004; 26:1104-1111.

21. Weiss G, Goodnough LT. Anemia of chronic disease. N Engl J Med. 2005; 352:1011-1023.

22. Sangoi MB, Guarda NS, Rodel AP, Zorzo P, Borges PO, Cargnin LP, De Carvalho JA, Premaor MO, Moresco RN. 
Prognostic value of red blood cell distribution width in prediction of in-hospital mortality in patients with acute myocardial infarction. Clin Lab. 2014; 60:1351-1356.

23. Lappe JM, Horne BD, Shah SH, May HT, Muhlestein JB, Lappe DL, Kfoury AG, Carlquist JF, Budge D, Alharethi R, Bair TL, Kraus WE, Anderson JL. Red cell distribution width, C-reactive protein, the complete blood count, and mortality in patients with coronary disease and a normal comparison population. Clin Chim Acta. 2011; 412:2094-2099.

24. Perlstein TS, Weuve J, Pfeffer MA, Beckman JA. Red blood cell distribution width and mortality risk in a communitybased prospective cohort. Arch Intern Med. 2009; 169:588-594.

25. Patel KV, Ferrucci L, Ershler WB, Longo DL, Guralnik JM. Red blood cell distribution width and the risk of death in middle-aged and older adults. Arch Intern Med. 2009; 169:515-523.
26. Li JS, Sexton DJ, Mick N, Nettles R, Fowler VJ, Ryan T, Bashore T, Corey GR. Proposed modifications to the Duke criteria for the diagnosis of infective endocarditis. Clin Infect Dis. 2000; 30:633-638.

27. Ma YC, Zuo L, Chen JH, Luo Q, Yu XQ, Li Y, Xu JS, Huang SM, Wang LN, Huang W, Wang M, Xu GB, Wang HY. Modified glomerular filtration rate estimating equation for Chinese patients with chronic kidney disease. J Am Soc Nephrol. 2006; 17:2937-2944.

28. DeLong ER, DeLong DM, Clarke-Pearson DL. Comparing the areas under two or more correlated receiver operating characteristic curves: a nonparametric approach. Biometrics. 1988; 44:837-845. 